\title{
Serum 25-hydroxyvitamin D levels are associated with carotid atherosclerosis in normotensive and euglycemic Chinese postmenopausal women: the Shanghai Changfeng study
}

\author{
Hui Ma ${ }^{1}$, Huandong Lin², Yu Hu${ }^{1}$, Xiaoming $\mathrm{Li}^{2}$, Wanyuan $\mathrm{He}^{3}$, Xuejuan $\mathrm{Jin}^{4}$, Jian Gao ${ }^{5}$, Naiqing Zhao ${ }^{6}$,
} Zhenqi Liu ${ }^{7}$ and Xin Gao ${ }^{2 *}$

\begin{abstract}
Background: The role of serum 25-hydroxyvitamin D $(25(\mathrm{OH}) \mathrm{D})$ in atherogenesis is unclear. We investigated whether the $25(\mathrm{OH})$ D is independently associated with the carotid intima-media thickness (CIMT) and carotid plaques in normotensive and euglycemic postmenopausal women.

Methods: A total of 671 normotensive and euglycemic postmenopausal women (mean age, 58.8 years) were enrolled from the Changfeng Study. A standard interview, anthropometrics measurements and laboratory analyses were performed for each participant. Bilateral CIMTs were measured using ultrasonography, and the presence of carotid plaques was assessed. The serum $25(\mathrm{OH})$ D was measured using electrochemiluminescence immunoassay.

Results: Serum $25(\mathrm{OH})$ D was $43.6 \pm 18.2 \mathrm{nmol} / \mathrm{L}$ in the postmenopausal women. Compared with subjects with 25 $(\mathrm{OH}) \mathrm{D}$ in the first, second and third quartiles, subjects with $25(\mathrm{OH}) \mathrm{D}$ in the fourth quartile had decreased CIMT and prevalence of carotid plaque $(0.684 \pm 0.009 \mathrm{~mm}$ vs $0.719 \pm 0.009 \mathrm{~mm}, 0.708 \pm 0.009 \mathrm{~mm}$ and $0.709 \pm 0.009 \mathrm{~mm}$; $10.8 \%$ vs $19.0 \%, 14.8 \%$ and $16.8 \%$, respectively). After adjusting for conventional CVD risk factors, PTH, liver and renal function, postmenopausal women with $25(\mathrm{OH}) \mathrm{D}$ in the fourth quartile still had lower CIMT than those in the first, second and third quartiles $(p=0.039)$ and the subjects in the fourth quartile had a 0.421 -fold decreased risk of carotid plaques relative to those in the lowest quartile (95\% confidence interval 0.209 to 0.848 ).
\end{abstract}

Conclusions: These results suggest serum $25(\mathrm{OH}) \mathrm{D}$ is independently and inversely associated with carotid atherosclerosis in postmenopausal women with normal blood pressure and normal glucose tolerance.

Keywords: 25-hydroxyvitamin D (25 (OH) D), Carotid intima-media thickness (CIMT), Carotid plaque, Carotid atherosclerosis

\section{Background}

Vitamin D, a fat-soluble vitamin and steroid hormone, is well known for its pivotal role in calcium homeostasis and bone metabolism. Beyond the role in bone health, vitamin $\mathrm{D}$ is receiving increasing attention for its influence on non-skeletal health problems and chronic diseases $[1,2]$. Serum 25-hydroxyvitamin D $(25(\mathrm{OH}) \mathrm{D})$, the major storage form of vitamin $\mathrm{D}$, is formed in the liver, and is a

\footnotetext{
* Correspondence: zhongshan_endo@126.com

2Department of Endocrinology and Metabolism, Zhong Shan Hospital, Fudan University, Shanghai 200032, China

Full list of author information is available at the end of the article
}

clinical indicator of overall vitamin D3 status [3]. The association of serum $25(\mathrm{OH})$ D levels with cardiovascular diseases (CVD) is debated in the literature. The Framingham Offspring Study revealed that low serum $25(\mathrm{OH}) \mathrm{D}$ was independently associated with an increased incidence of CVD in Caucasians during a 5.4-year follow-up period [4]. Additionally, European studies have shown that serum $25(\mathrm{OH})$ D levels are inversely associated with the prevalence of CVD and carotid intima-medial thickening in patients with type 2 diabetes mellitus (DM) [5]. More recently, the meta-analysis by Wang et al. [6] of nineteen independent prospective 
cohort studies reported an inverse association between serum $25(\mathrm{OH})$ D concentrations and risk of CVD outcome. However, several other studies observed no significant association between serum $25(\mathrm{OH})$ D levels and CVD. For example, Deleskog $\mathrm{A}$ et al and Blondon $\mathrm{M}$ et al demonstrated that levels of $25(\mathrm{OH})$ $\mathrm{D}$ showed multiple associations with established and emerging cardiovascular risk factors but were not consistently, independently related to measures of carotid IMT and carotid plaque[7,8]. The Korean National Health and Nutrition Examination Survey (KNHANES-2008-2009) indicates that the prevalence of CVD is not associated with low serum $25(\mathrm{OH})$ D levels in the total population [9]. The study by Melamed et al. [10], using the third National Health and Nutrition Examination Survey cohort, while CVD risk was not statistically significant, the all-cause mortality data suggested a $U$ - or reverse J-shaped dose-relationship, with increased total mortality for both the lowest and highest serum $25(\mathrm{OH}) \mathrm{D}$ concentrations $(<44.4$ and $>80.1 \mathrm{nmol} / \mathrm{l}$, respectively $)$ in this cohort followed for 9 years. As noted, the majority of the previous studies were conducted using populations with different proportions of hypertension or diabetes. In addition, $25(\mathrm{OH}) \mathrm{D}$ is associated with hyperglycemia and hypertension [11], which may themselves be linked to CVD. Therefore, the association between $25(\mathrm{OH}) \mathrm{D}$ and atherosclerosis may be confounded by the inclusion of subjects with hypertension, diabetes or pre-diabetes. Moreover, it has been shown that $25(\mathrm{OH}) \mathrm{D}$ values vary between different ethnicities. There are few reports on the relationship between $25(\mathrm{OH}) \mathrm{D}$ and CVD in the Chinese postmenopausal women. Given the high risk of CVD in this population [12], more evidence is needed to evaluate the association between $25(\mathrm{OH}) \mathrm{D}$ and atherosclerosis in the Chinese postmenopausal women.

The use of high-resolution color-coded duplex sonography offers the opportunity to assess the carotid intima-media thickness (CIMT) and carotid plaques as reliable markers of atherosclerosis [13]. Therefore, in the present study, we investigated the relationship between $25(\mathrm{OH}) \mathrm{D}$ and carotid atherosclerosis in a community-based population of normotensive and euglycemic postmenopausal women.

\section{Methods}

\section{Study population}

The subjects were participants in the Changfeng Study, a community-based study of chronic diseases among middle-aged and elderly individuals which has been described elsewhere [14]. The Changfeng community is a middle-class community in Shanghai [14]. From June 2009 to June 2012, 2717 postmenopausal women were initially enrolled. We excluded 2046 participants for the following reasons: lack of physical examination and laboratory assessments $(\mathrm{n}=51)$, prevalent CVD (myocardial infarction, stroke, or peripheral arterial disease) $(\mathrm{n}=202)$, prevalent hemodialysis $(\mathrm{n}=2)$, bone fracture within 3 months and use of drugs known to influence bone metabolism including the use of postmenopausal hormone therapy, calcium, diphosphonate, vitamin $\mathrm{D}$ and glucocorticoid $(\mathrm{n}=384)$, prevalent hypertension (systolic blood pressure $\geq 140 \mathrm{mmHg}$, diastolic blood pressure $\geq 90 \mathrm{mmHg}$, the use of antihypertensive medications, or diagnosed hypertension) $(\mathrm{n}=1076)$, prevalent diabetes mellitus or pre-diabetes (fasting glucose $\geq 5.6 \mathrm{mmol} / \mathrm{L}$, OGTT $2 \mathrm{~h}$ glucose $\geq 7.8 \mathrm{mmol} / \mathrm{L}$, the use of hypoglycaemic medications, or diagnosed diabetes; $\mathrm{n}=320$ ), or the use of lipid-lowering therapy or use of the antiplatelet agents $(n=11)$. Finally, 671 subjects were included in the analysis.

The study was approved by the ethical committee of Zhongshan Hospital, Fudan University and was conducted in accordance with the guidelines of the Declaration of Helsinki. All the patients provided consent upon enrolment in the study. Interviews, physical examinations and ultrasound scans were performed at the Changfeng Community Health Service Center.

\section{Clinical measurements}

Letters were sent to participants with instructions asking them not to alter their diet or level of physical activity for at least 3 days before the test. A questionnaire was administered by trained nurses to evaluate the medical history and lifestyle of each participant. Weight and height were measured while the participant was clothed in a light gown. The body mass index (BMI) was calculated as the weight divided by the height squared $\left(\mathrm{kg} / \mathrm{m}^{2}\right)$. The waist circumference was measured midway between the lowest rib margin and the iliac crest in a standing position, and the hip circumference was measured at the widest level over the greater trochanters. The waist-to-hip ratio (WHR) was calculated as the waist circumference divided by the hip circumference. The resting blood pressure was measured three times, and the mean value was used for the analysis. Blood samples were obtained after a fasting period of at least 10 hours. Total cholesterol (TC), high-density lipoprotein cholesterol (HDL-C), triglycerides (TG) and liver enzymes were measured using a model 7600 automated bio-analyser (Hitachi, Tokyo, Japan). The level of low-density lipoprotein cholesterol (LDL-C) was calculated using the Friedewald equation. The fasting blood glucose (FBG) and $2 \mathrm{~h}$ glucose levels following a 75-g oral glucose challenge (PPG) for non-diabetics were measured using the glucose oxidase method. The glomerular filtration rate (GFR) was estimated based on the serum creatinine concentration using the Modification of Diet in Renal Disease (MDRD) formula: estimated GFR $(\mathrm{eGFR})=186 \times$ [serum creatinine 
$(\mathrm{mmol} / \mathrm{L}) \times 0.0113]^{-1.154} \times$ age $^{-0.203} \times(0.742$ for women $)[15]$. The serum $25(\mathrm{OH}) \mathrm{D}$, parathyroid hormone $(\mathrm{PTH})$ and insulin were measured by electrochemiluminescence immunoassay using an immunoassay analyzer (Roche Cobas-6001, Switzerland; coefficient of variation $<4.0 \%,<5.0 \%$ and $<5.0 \%$, respectively). Homeostasis model assessment index for insulin resistance (HOMA-IR) and beta cell function (HOMA-\%B) were used to estimate insulin sensitivity and insulin secretion [16].

The carotid arteries of the participants were evaluated by an experienced radiologist who was blinded to the participants' details using a GE Logic P5 (GE Healthcare, Milwaukee, USA) scanner with a $10-\mathrm{MHz}$ probe. The CIMTs on both sides were measured in the common carotid artery approximately $1 \mathrm{~cm}$ proximal to the bifurcation at the far wall during end diastole. The CIMT was quantified at plaque-free sections of the carotid arteries as the distance between the lumen-intima and media-adventitia interfaces. Three values were measured on each side, and the average CIMT values were used for the analysis. The study procedure involved scanning the near and far walls of both common carotid arteries, the carotid bifurcation, and the internal carotid artery for the presence of plaques, defined as the presence of focal wall thickening resulting in a thickness that is at least $50 \%$ greater than that of the surrounding vessel wall or as a focal region with a CIMT greater than $1.5 \mathrm{~mm}$ that protrudes into the lumen that is distinct from the adjacent boundary, according to American Society of Echocardiography [17]. Repeated measurements on the same subjects (performed in 104 subjects) for CIMT and carotid plaque yielded an intraclass correlation coefficient (ICC) of 95\% (95\% confidence interval, 0.91 to 0.97 ) and $96 \%$ (95\% confidence interval, 0.92 to 0.97 ), respectively.

Hypertension was defined according to the Seventh Report of the Joint National Committee [18]. The diagnoses of impaired fasting glucose, impaired glucose tolerance, and DM were based on the American Diabetes Association 2010 criteria [19]. The diagnosis of cardiovascular disease was based on self-reports and confirmed using hospital medical records.

\section{Statistical analyses}

The data were expressed as the means $\pm \mathrm{SD}(\mathrm{SE})$, frequencies or medians with 25th and 75th percentiles. Skewed variables were logarithmically transformed to improve normality prior to analysis. To evaluate the relationship between each parameter and the $25(\mathrm{OH}) \mathrm{D}$, the subjects were stratified according to the $25(\mathrm{OH}) \mathrm{D}$ quartiles. The ranges of $25(\mathrm{OH}) \mathrm{D}$ in the quartiles were 12.4-30.7, $30.8-40.5,40.6-53.0$ and 53.2-153.0 nmol/L. Analysis of covariance and logistic regression, with adjustments for CVD risk factors, liver enzymes and the GFR were conducted to compare means and proportions, respectively, across the $25(\mathrm{OH}) \mathrm{D}$ quartiles. We used a general linear model analyses and complete the homogeneity tests, in which the outcome is the CIMT value of comparison among $25(\mathrm{OH}) \mathrm{D}$ quartiles. We test the null hypothesis that the error variance of the dependent variable is equal across groups and get the result that $\mathrm{p}=0.366$. Regression coefficients and odds ratios (ORs) were calculated for a 1-unit increase in 25(OH)D. SPSS 16.0 for Windows (SPSS 16.0 Inc Chicago, IL, USA)) was used to perform the statistical analyses. All statistical tests were two tailed, and p-values less than 0.05 were considered significant.

\section{Results}

\section{Characteristics of the subjects according to the 25(OH)D} quartiles

A total of 671 postmenopausal women were evaluated. The mean value of CIMT was $0.703 \pm 0.123 \mathrm{~mm}$. The prevalence of carotid plaques was $15.4 \%$. The mean value of $25(\mathrm{OH}) \mathrm{D}$ was $43.6 \pm 9.2 \mathrm{nmol} / \mathrm{L}$. A total of $1.5 \%$ of the subjects was current smokers. Table 1 shows the clinical and biochemical parameters according to the quartiles groups for the $25(\mathrm{OH}) \mathrm{D}$. When the traditional CVD risk factors were examined, WHR, DBP, PPG and PTH were significantly associated with the $25(\mathrm{OH}) \mathrm{D}$ quartiles. Other parameters were not significantly different among the groups.

\section{Association of the anthropometric and biochemical parameters with serum 25(OH)D levels}

Linear regression analysis showed an association between 25(OH)D and BMI, WHR, DBP, PPG and PTH (Table 2). Multivariate linear stepwise regression analysis was performed to evaluate the independent factors of 25 $(\mathrm{OH}) \mathrm{D}$. The analysis demonstrated that age (standardized $\beta=0.082, \quad p=0.028$ ), PTH (standardized $\beta=-0.334$, $\mathrm{p}<0.001$ ), BMI (standardized $\beta=-0.141, \mathrm{p}=0.001$ ) and PPG (standardized $\beta=-0.053, p=0.003$ ) were independently associated with serum $25(\mathrm{OH}) \mathrm{D}$.

\section{Association between carotid atherosclerosis and 25(OH)D}

Table 3 presents the CIMT of the subjects according to $25(\mathrm{OH}) \mathrm{D}$ quartile groups. Compared with the subjects in the first, second and third $25(\mathrm{OH}) \mathrm{D}$ quartiles, those in the fourth quartile had significantly thinner CIMTs $(0.684 \pm 0.009 \mathrm{~mm}$ vs $0.719 \pm 0.009 \mathrm{~mm}, 0.708 \pm$ $0.009 \mathrm{~mm}$ and $0.709 \pm 0.009 \mathrm{~mm}$, respectively). After adjusting for conventional CVD risk factors, liver enzymes and the GFR, the subjects with $25(\mathrm{OH}) \mathrm{D}$ in the fourth quartile still had lower CIMT than those in the first, second and third quartiles $(\mathrm{p}=0.039)$.

Compared with the subjects in the first, second and third 25(OH)D quartiles, those in the fourth quartile had significantly lower prevalence of carotid plaque $(10.8 \%$ 
Table 1 Characteristics of the subjects according to quartiles groups for 25(OH)D in subjects

\begin{tabular}{|c|c|c|c|c|c|c|}
\hline Variables & All $(n=671)$ & $\begin{array}{c}1^{\text {st }} \text { quartile } \\
(n=168)\end{array}$ & $\begin{array}{c}2^{\text {nd }} \text { quartile } \\
(n=169)\end{array}$ & $\begin{array}{c}3^{\text {rd }} \text { quartile } \\
(n=167)\end{array}$ & $\begin{array}{c}4^{\text {th }} \text { quartile } \\
(n=167)\end{array}$ & $\mathrm{P}$ among groups \\
\hline $25(\mathrm{OH}) \mathrm{D}$ range $(\mathrm{nmol} / \mathrm{L})$ & $12.4-153.0$ & $12.4-30.7$ & $30.8-40.5$ & $40.6-53.0$ & $53.2-153.0$ & \\
\hline Age (ys) & $58.8(7.5)$ & $57.9(7.4)$ & 59.5(7.5)a & $58.9(7.0)$ & $59.0(8.0)$ & 0.255 \\
\hline BMI $\left(\mathrm{kg} / \mathrm{m}^{2}\right)$ & $22.8(2.9)$ & $22.9(2.9)$ & $22.8(2.8)$ & 23.1(3.1) & $22.4(2.8) c$ & 0.238 \\
\hline WHR & $0.853(0.063)$ & $0.846(0.052)$ & $0.855(0.061)$ & $0.847(0.061)$ & $0.863(0.074) a, c$ & 0.042 \\
\hline Current smoker, n (\%) & $10(1.5 \%)$ & $4(2.4 \%)$ & $3(1.8 \%)$ & $1(0.6 \%)$ & $2(1.2 \%)$ & 0.572 \\
\hline $\mathrm{SBP}(\mathrm{mmHg})$ & $120.0(11.1)$ & 119.7(11.8) & $120.8(11.1)$ & $120.8(10.3)$ & 118.7(11.1) & 0.253 \\
\hline $\mathrm{DBP}(\mathrm{mmHg})$ & $70.4(7.5)$ & 71.2(7.6) & $70.0(7.2)$ & 71.3(7.3) & $69.1(7.8) \mathrm{a}, \mathrm{c}$ & 0.023 \\
\hline $\mathrm{ALT}(\mathrm{U} / \mathrm{L})$ & $16.9(9.5)$ & 15.6(7.6) & $16.4(7.2)$ & 17.6(7.1) & 17.8(7.5)a & 0.107 \\
\hline AST (U/L) & $21.1(6.1)$ & $20.5(6.9)$ & $20.7(5.5)$ & $21.4(5.5)$ & $21.7(6.5)$ & 0.246 \\
\hline $\mathrm{TC}(\mathrm{mmol} / \mathrm{L})$ & $5.2(0.8)$ & $5.2(0.8)$ & $5.3(0.9)$ & $5.4(0.9)$ & $5.2(0.7) \mathrm{C}$ & 0.130 \\
\hline LDL-c (mmol/L) & $3.0(0.7)$ & $3.0(0.8)$ & $3.0(0.7)$ & $3.1(0.8)$ & $2.9(0.7) \mathrm{C}$ & 0.096 \\
\hline $\mathrm{HDL}-\mathrm{c}(\mathrm{mmol} / \mathrm{L})$ & $1.6(0.4)$ & $1.6(0.4)$ & $1.6(0.4)$ & $1.6(0.4)$ & $1.6(0.4)$ & 0.605 \\
\hline $\mathrm{TG}(\mathrm{mmol} / \mathrm{L})$ & $1.4(0.7)$ & $1.3(0.6)$ & $1.3(0.6)$ & $1.4(0.8)$ & $1.4(0.7)$ & 0.467 \\
\hline $\mathrm{FBG}(\mathrm{mmol} / \mathrm{L})$ & $4.9(0.3)$ & $4.9(0.3)$ & $4.9(0.4)$ & $4.9(0.3)$ & $4.9(0.3)$ & 0.516 \\
\hline PPG (mmol/L) & $5.7(1.1)$ & $5.9(1.1)$ & $5.5(1.0) a$ & 5.4(1.0)a & 5.4(0.9)a & $<0.001$ \\
\hline PTH $(\mathrm{pg} / \mathrm{mL})$ & $42.2(15.1)$ & $48.6(16.3)$ & 42.9(13.6)a & 41.4(14.5)a & 35.7(12.9)a,b,c & $<0.001$ \\
\hline HOMA-IR & $1.4(1.0-1.9)$ & $1.3(1.0-2.0)$ & $1.5(1.1-2.0)$ & $1.5(1.0-2.0)$ & $1.4(1.0-1.8)$ & 0.425 \\
\hline HOMA-B \% & $97.4(72.7-128.6)$ & $92.1(71.4-127.8)$ & 98.6(75.6-131.0)a & $102.1(70.8-134.7)$ & $97.5(73.4-122.9)$ & 0.1 \\
\hline GFR $\left(\mathrm{ml} / \mathrm{min}\right.$ per $\left.1.73 \mathrm{~m}^{2}\right)$ & $96.9(18.9)$ & $98.3(19.0)$ & $96.2(19.2)$ & 97.4(19.8) & $96.0(17.6)$ & 0.647 \\
\hline
\end{tabular}

Data are mean (SD) or percentage of subjects or median (interquartile range).

BMI: body mass index, WHR: waist-hip-ratio, FBG: Fasting blood glucose, PPG: OGTT 2 h blood glucose, PTH: parathyroid hormone, SBP: systolic blood pressure, DBP: diastolic blood pressure, ALT: alanine transaminase, AST: aspartate transaminase, TC: Total cholesterol, TG: triglyceride, HDL-C: high density lipoprotein cholesterol, LDL-C: low density lipoprotein cholesterol, HOMA-IR: homeostasis model assessment index for insulin resistance, HOMA-B: homeostasis model assessment index for beta cell function, GFR: glomerular filtration rate.

a Analysis of variance with LSD post-hoc test or Chi-square statistical analysis: $P<0.05$ versus 1 st quartile.

b Analysis of variance with LSD post-hoc test or Chi-square statistical analysis: $\mathrm{P}<0.05$ versus 2 nd quartile.

c Analysis of variance with LSD post-hoc test or Chi-square statistical analysis: $\mathrm{P}<0.05$ versus 3rd quartile.

vs $19.0 \%, 14.8 \%$ and $16.8 \%$, respectively). After adjusting for conventional CVD risk factors, liver enzymes and the GFR, the subjects with $25(\mathrm{OH}) \mathrm{D}$ in the fourth quartile had 0.421-fold decreased risks for carotid plaques relative to those in the lowest quartile (95\% confidence interval 0.209 to 0.848 ) (Figure 1 ).

\section{Discussion}

Our study showed that serum $25(\mathrm{OH}) \mathrm{D}$ was independently associated with carotid atherosclerosis in normotensive and euglycemic Chinese postmenopausal women. The CIMT and the prevalence of carotid plaques significantly decreased with increasing serum 25(OH)D levels after adjusting for conventional CVD risk factors, PTH, liver enzymes and renal function in the subjects.

Serum 25(OH)D has recently become an interesting topic in cardiovascular researches [1-6]. Although a number of studies have demonstrated that $25(\mathrm{OH}) \mathrm{D}$ is associated with the development of cardiovascular events, it is still conflicting whether there is an independent association between $25(\mathrm{OH}) \mathrm{D}$ and atherosclerotic CVD. The participants in the Framingham Offspring Study [4] had $40 \%$ patients with hypertension and $8 \%$ diabetic patients. European studies [5] were performed in diabetic adults. The studies eligible for inclusion in the metaanalysis by Wang [6], the study by Deleskog A [7], Blondon M [8], Melamed [10] and the Korean National Health and Nutrition Examination Survey [9] enrolled study populations with different proportions of hypertension or diabetes. As noted, recent studies have demonstrated that there was a close association between $25(\mathrm{OH}) \mathrm{D}$ and cardiovascular risk factors, such as hyperglycemia and hypertension [11]. Studies suggest vitamin D deficiency may be a contributor to the development of CVD potentially through associations with diabetes or hypertension [20]. In line with previous studies [11], serum 25(OH)D concentrations were inversely associated with blood pressure and blood glucose in the present study. Therefore, the relationship between carotid atherosclerosis and serum 25(OH)D would be affected by the chronic effects of increased blood glucose levels and blood pressure. The impact of residual confounding factors would remain after adjusting for hyperglycemia and hypertension in previous studies. To eliminate the confounding effects 
Table 2 Association of the anthropometric and biochemical parameters with serum 25(OH)D levels in postmenopausal women

\begin{tabular}{|c|c|c|c|}
\hline & $\beta(95 \% \mathrm{Cl})$ & Standardized $\beta$ & $\mathbf{P}$ \\
\hline Age (per 1y) & $0.154(-0.029-0.338)$ & 0.064 & 0.1 \\
\hline BMI (per 1 units) & $-0.593(-1.063--0.123)$ & -0.095 & 0.013 \\
\hline WHR & $25.129(3.130-47.128)$ & 0.086 & 0.025 \\
\hline Current smoking & $-5.456(-16.840-5.928)$ & -0.036 & 0.347 \\
\hline SBP (per 1 mmHg) & $-0.104(-0.229-0.020)$ & -0.064 & 0.1 \\
\hline $\mathrm{DBP}$ (per $1 \mathrm{mmHg}$ ) & $-0.272(-0.455--0.09)$ & -0.112 & 0.004 \\
\hline $\operatorname{ALT}(1 \mathrm{U} / \mathrm{L})$ & $0.130(-0.014-0.275)$ & 0.068 & 0.077 \\
\hline AST (1U/L) & $0.161(-0.064-0.386)$ & 0.054 & 0.161 \\
\hline TC (1 mmol/L) & $-0.679(-2.323-0.965)$ & -0.031 & 0.418 \\
\hline LDL-C (1 mmol/L) & $-1.199(-3.044-0.646)$ & -0.049 & 0.202 \\
\hline $\mathrm{HDL}-\mathrm{C}(1 \mathrm{mmol} / \mathrm{L})$ & $-1.489(-5.121-2.143)$ & -0.031 & 0.421 \\
\hline TG (1 mmol/L) & $-1.838(-2.788-0.111)$ & -0.071 & 0.065 \\
\hline FBG (1 mmol/L) & $-2.853(-6.953-1.247)$ & -0.053 & 0.172 \\
\hline PPG (1 mmol/L) & $-2.569(-3.862--1.275)$ & -0.149 & 0.001 \\
\hline PTH (1 pg/mL) & $-0.408(-0.494--0.322)$ & -0.338 & $<0.001$ \\
\hline $\log H O M A-I R$ & $-4.853(-11.222-1.516)$ & -0.058 & 0.135 \\
\hline $\log \mathrm{HOMA}-\mathrm{B} \%$ & $1.779(-0.079-3.480)$ & 0.025 & 0.125 \\
\hline GFR (1 ml/min per $1.73 \mathrm{~m} 2)$ & $-0.052(-0.125-0.021)$ & -0.054 & 0.161 \\
\hline
\end{tabular}

BMI: body mass index, WHR: waist-hip-ratio, FBG: Fasting blood glucose, PPG: OGTT 2 h blood glucose, PTH: parathyroid hormone, SBP: systolic blood pressure, $D B P$ : diastolic blood pressure, $A L T$ : alanine transaminase, $A S T$ : aspartate transaminase, $T C$ : Total cholesterol, TG: triglyceride, HDL-C: high density lipoprotein cholesterol, $L D L-C$ : low density lipoprotein cholesterol, HOMA-IR: homeostasis model assessment index for insulin resistance, $H O M A-B$ : homeostasis model assessment index for beta cell function, GFR: glomerular filtration rate.

of hyperglycemia and hypertension on the relationship between carotid atherosclerosis and serum $25(\mathrm{OH}) \mathrm{D}$, we explored the relationship in the subjects with normal blood pressure and normal glucose tolerance. Thus, the association between $25(\mathrm{OH}) \mathrm{D}$ and carotid atherosclerosis was not confounded by hyperglycemia and hypertension.

In the present study there was an independent association between 25(OH)D and CIMT after adjusting for established cardiovascular risk factors. As we known, CIMT may be affected both by atherosclerosis and wall hypertrophy, we also assessed the association between 25(OH)D and carotid plaque, which may be more representative of atherosclerosis than CIMT and more informative for predicting cardiovascular risk [21]. We demonstrated a negative and independent relationship between 25 $(\mathrm{OH}) \mathrm{D}$ and carotid plaque, independently from the traditional risk factors. In contrast, Deleskog A et al [7] reported that there were no independent relationships between $25(\mathrm{OH}) \mathrm{D}$ and the baseline and progression measures of carotid IMT in 3430 middle-aged and elderly

Table 3 CIMT in the subjects according to quartile groups for 25(OH)D in the subjects

\begin{tabular}{|c|c|c|c|c|c|}
\hline & \multicolumn{5}{|c|}{ Quartile groups for $25(\mathrm{OH}) \mathrm{D}$ in the subjects } \\
\hline & $1^{\text {st }}$ quartile & $2^{\text {nd }}$ quartile & $3^{\text {rd }}$ quartile & $4^{\text {th }}$ quartile & $p$ \\
\hline \multicolumn{6}{|l|}{ Unadjusted } \\
\hline CIMT (mm) & 0.719(0.009) & $0.708(0.009)$ & $0.709(0.009)$ & $0.684(0.009) a, b, c$ & 0.034 \\
\hline \multicolumn{6}{|l|}{ Model I } \\
\hline CIMT (mm) & $0.712(0.009)$ & $0.704(0.009)$ & $0.707(0.009)$ & $0.688(0.009) a, b, c$ & 0.039 \\
\hline
\end{tabular}

Data are mean (SE).

a Analysis of variance with LSD (least significant difference) post-hoc test: $P<0.05$ versus 1 st quartile.

b Analysis of variance with LSD post-hoc test: $P<0.05$ versus 2 nd quartile.

c Analysis of variance with LSD post-hoc test: $P<0.05$ versus 3 rd quartile.

Model I: adjusting for age, FBG (fasting blood glucose), PPG (postprandial blood glucose), PTH(parathyroid hormone), BMI (body mass index), WHR (waist-to-hip ratio), current smoking, SBP (systolic blood pressure), DBP (diastolic blood pressure), ALT(alanine transaminase), $A S T$ (aspartate transaminase), $T G$ (triglyceride), $H D L-C$ (high-density lipoprotein cholesterol), LDL-C (low-density lipoprotein cholesterol), logHOMA-IR (homeostasis model assessment index for insulin resistance), logHOMA-\%B (homeostasis model assessment index for beta cell function) and GFR(glomerular filtration rate).

CIMT: carotid intima-media thickness, $25(\mathrm{OH})$ D: 25-hydroxyvitamin D. 


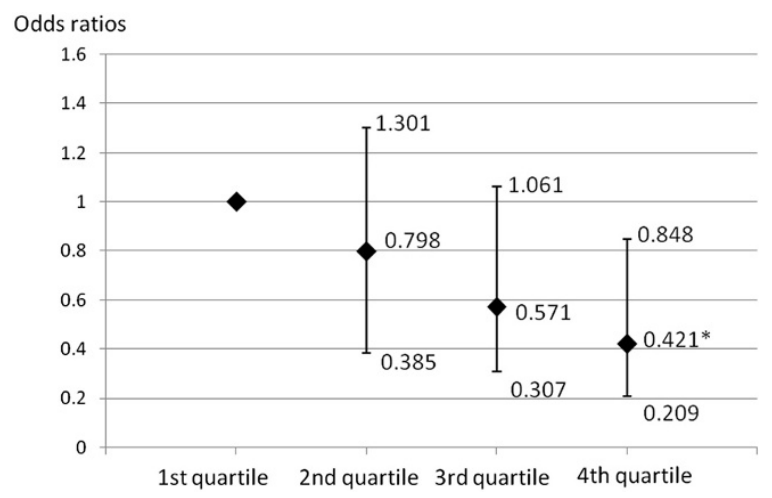

Figure 1 ORs of carotid plaque in the subjects across the $25(\mathrm{OH}) \mathrm{D}$ quartile. ORs of carotid plaque in the subjects according to $25(\mathrm{OH}) \mathrm{D}$ quartile groups after adjusting for age, BMI, WHR, FBG, PPG, SBP, DBP, TG, HDL-C, LDL-C, smoking, ALT, AST, PTH, logHOMA-IR, logHOMA-B\% and the GFR, respectively. ${ }^{*}$ Analysis of variance with logistic regression analysis: $\mathrm{P}<0.05$ versus 1 st quartile ORs and $95 \% \mathrm{Cl}$ are shown.

subjects with high cardiovascular risk but no prevalent CVD. Similarly, Blondon $\mathrm{M}$ et al [8] evaluated the associations of $25(\mathrm{OH}) \mathrm{D}$ with CIMT and carotid plaques among 3251 participants free of cardiovascular disease in the Multi-Ethnic Study of Atherosclerosis and observed consistent null results for both cross-sectional associations and longitudinal associations evaluating change in IMT and incident plaque during 10 years of follow-up. Several explanations could be involved in the above different results. First, the BMI, blood pressure, blood glucose and lipid profile of the subjects in our study were relatively improved in comparison with those in the above studies. In addition, our subjects had a lower proportion of smoking participants. Thus, the association between 25(OH)D and CVD in subjects with higher cardiovascular risk may be weakened for the greater contribution of traditional atherosclerotic risks to CVD in the studies of Deleskog A [7] and Blondon $M$ [8]. Second, there may be sex-related differences in the association between $25(\mathrm{OH}) \mathrm{D}$ and CVD. These sex-related differences might depend on background data. It is known that the life-long risk for CVD is higher for men than women [22]. Third, it is necessary to take ethnic differences into account.

$69.9 \%$ of subjects have $25(\mathrm{OH}) \mathrm{D}$ levels below $50 \mathrm{nmol} / \mathrm{L}$. Similarly, another study in China evaluated vitamin D status of healthy adults living in Guiyang (latitude $26.5^{\circ}$ north). The study showed that the average serum $25(\mathrm{OH}) \mathrm{D}$ level of $20.4 \mathrm{ng} / \mathrm{mL}(51 \mathrm{nmol} / \mathrm{L})$ and serum $25(\mathrm{OH}) \mathrm{D}$ was below $50 \mathrm{nmol} / \mathrm{L}$ in $52.3 \%$ [23]. Lu L et al [24] measured plasma $25(\mathrm{OH}) \mathrm{D}$ was in a cross-sectional sample of 1,443 men and 1,819 women aged 50-70 years from Beijing (latitude $40^{\circ}$ north) and Shanghai (latitude $31^{\circ}$ north). The median value of plasma 25(OH)D was $35.6 \mathrm{nmol} / \mathrm{l}$ in Beijing and
$47.6 \mathrm{nmol} / \mathrm{l}$ in Shanghai, and the percentages of vitamin D deficiency, insufficiency, and sufficiency were 69.2, 24.4, and $6.4 \%$, respectively. Indeed, poor vitamin D status in middle and older Chinese individuals was also reported previously in two small bone related studies conducted in Beijing [25] and Shenyang [26]. The above data suggested that vitamin $\mathrm{D}$ deficiency was common in middle-aged and elderly Chinese individuals. Another explanation is the exclusion criteria of the intake of the vitamin D supplements in our study. Additionally, unlike in the United States and other western countries, a racial/ethnic difference may be exist in the levels of $25(\mathrm{OH}) \mathrm{D}$ concentrations. Although little is known regarding to the high prevalence of vitamin D deficiency in our population, the criteria of vitamin D deficiency in Chinese may differ from that in the western population.

The mechanisms responsible for the independent relationship between $25(\mathrm{OH}) \mathrm{D}$ and atherosclerosis have not been well elucidated. In our study, 25(OH)D was negatively associated with BMI, DBP and PPG. These findings were also supported by other studies [27-29]. Therefore, the beneficial effects of 25(OH)D on atherosclerosis might be attributed to its ability to improve the glucose metabolism and blood pressure control. On the other hand, in the present study, we demonstrated an inversely and independent association between 25(OH)D and carotid atherosclerosis after adjustment for established CVD risk factors, PTH, liver and renal function in postmenopausal women with normal blood pressure and normal glucose tolerance. If $25(\mathrm{OH}) \mathrm{D}$ and the other risk factors share a common causal pathway, adjusting for these risk factors may attenuate the relationship between $25(\mathrm{OH}) \mathrm{D}$ and carotid atherosclerosis. However, 25(OH)D remained a relatively strong predictor after full adjustment in our study, suggesting that there was an independent additive component in the relationship between $25(\mathrm{OH}) \mathrm{D}$ and CVD. Thus, other atherogenic mechanisms could conceivably be involved. Because many cell types involved in cardiovascular function like cardiomyocytes, endothelial cells, or vascular smooth muscle cells express vitamin D receptors, a direct influence of vitamin $\mathrm{D}$ on the cardiovascular system can be assumed [30]. There are several mechanisms proposed to explain the inverse relationship between vitamin D and CVD. First, activated vitamin $\mathrm{D}$ is an inhibitor of the renin-angiotensin system [31]. Vitamin D deficiency predisposes to up-regulation of the renin-angiotensin-aldosterone system and hypertrophy of the vascular smooth muscle cells $[20,32]$. Second, Vitamin D has effects that may favorably influence cardiovascular system through strengthen in insulin secretion and insulin sensitivity [33], down-regulate coagulation through the up-regulation of thrombomodulin [34], down-regulate vascular calcification [35-37] and modulation of inflammatory processes [38]. Third, 
long-term vitamin $\mathrm{D}$ insufficiency and deficiency cause secondary hyperparathyroidism, which in turn may mediate many of the detrimental CV effects including increasing systemic inflammation, as indicated by increased levels of C-reactive protein, homocysteine, and interleukin10 [32]. Fourth, vitamin D may play a pivotal role in cardiac function. Cardiac muscle cells possess a vitamin D receptor and a 1,25-dihydroxyvitaminD-dependent calcium-binding protein. Vitamin D has effects on extra- cellular matrix remodeling, myocardial cell hypertrophy, and proliferation $[20,39]$. Vitamin D deficiency predisposes to lead to hypertrophy of the left ventricle. Fifth, activated vitamin D may also retard atherosclerosis by inhibiting macrophage cholesterol uptake and foam cell formation [40].

Our results suggest that $25(\mathrm{OH}) \mathrm{D}$ is a marker or risk factor for atherosclerosis. $25(\mathrm{OH}) \mathrm{D}$ could be adopted as an additional marker of the detection of CVD and the implementation of interventions. An early evaluation of the $25(\mathrm{OH}) \mathrm{D}$ would be advantageous for the early detection of CVD, and individuals with decreased 25 $(\mathrm{OH}) \mathrm{D}$ might benefit from more aggressive lifestyle modifications and food-based strategies.

We recognize several limitations of this study: it is crosssectional, and the $25(\mathrm{OH}) \mathrm{D}$ was assessed based on a single morning fasting blood sample. We also acknowledge that in this analysis we do not have data on hours of sunlight per day, albumin and vitamin $\mathrm{D}$ binding protein. The cross-sectional nature of this study limits our ability to determine causality. The potential confounding factors remain, particularly in the absence of data for physical activity and socio-economic status. However, the temporal relationship between the $25(\mathrm{OH}) \mathrm{D}$ and carotid atherosclerosis has been well established. Our participants were postmenopausal women, and therefore, the results cannot be applied to younger subjects. Hence, the association between 25 $(\mathrm{OH}) \mathrm{D}$ and carotid atherosclerosis should be confirmed using a larger sample and in prospective studies.

\section{Conclusions}

In conclusion, we demonstrated that $25(\mathrm{OH}) \mathrm{D}$ has a negatively correlation with carotid atherosclerosis even after adjusting for conventional CVD risk factors, PTH, liver and renal function in postmenopausal women with normal blood glucose levels and normal blood pressure. Our findings suggest that individuals with decreased 25 $(\mathrm{OH}) \mathrm{D}$ require aggressive management of CVD risk factors. Should causality be affirmed by ongoing and future studies, there are food-based strategies for enhanced vitamin $\mathrm{D}$ status in the population which could ultimately lower risk of CVD.

\footnotetext{
Abbreviations

25(OH)D: 25-hydroxyvitamin D; CIMT: Carotid intima-media thickness; CVD: Cardiovascular disease; BMI: Body mass index; WHR: Waist-hip-ratio; FBG: Fasting blood glucose; PPG: OGTT 2 h blood glucose; PTH: Parathyroid
}

hormone; SBP: Systolic blood pressure; DBP: Diastolic blood pressure; ALT: Alanine transaminase; AST: Aspartate transaminase; TC: Total cholesterol; TG: Triglyceride; HDL-C: High density lipoprotein cholesterol; LDL-C: Low density lipoprotein cholesterol; HOMA-IR: Homeostasis model assessment index for insulin resistance; HOMA-B: Homeostasis model assessment index for beta cell function; GFR: Glomerular filtration rate.

\section{Competing interests}

The authors declare that they have no competing interests.

\section{Authors' contributions}

Conceived and designed the experiments: HM HDL XML YH XJJ JG NQZ ZQL XG. Performed the experiments: HM HDL XML WYH JG. Analyzed the data: HM NQZ JG. Wrote the paper: HM XG. All authors read and approved the final manuscript.

\section{Acknowledgments}

The Shanghai Changfeng Study has also received great support from Changfeng Health Center, the Health Bureau of Putuo District, and the committees of all the sub-communities of Changfeng. The contributions of all the working staffs and inhabitants are greatly acknowledged. This work was supported by grants from the Major State Basic Research Development Program of China (2012CB524906 to X.G.; http://www.973.gov.cn/Default_3. aspx), National Natural Science Foundation of China (81270933 to X.G.), the Major Project of Subject Construction of Shanghai Bureau of Health (Grant No. 2013ZYJB0802 to X. Gao).

\section{Author details}

'Department of Geriatrics, Zhong Shan Hospital, Fudan University, Shanghai 200032, China. ${ }^{2}$ Department of Endocrinology and Metabolism, Zhong Shan Hospital, Fudan University, Shanghai 200032, China. ${ }^{3}$ Department of Ultrasonography, Zhongshan Hospital, Fudan University, Shanghai 200032, China. ${ }^{4}$ Clinical Epidemiology Center, Zhong Shan Hospital, Fudan University, Shanghai 200032, China. ${ }^{5}$ Department of Clinical Nutrition, Zhong Shan Hospital, Fudan University, Shanghai 200032, China. ${ }^{6}$ Department of Biostatistics, College of Public Health, Fudan University, Shanghai 200032, China. ${ }^{7}$ Division of Endocrinology and Metabolism, Department of Medicine, University of Virginia Health System, Charlottesville, Virginia, USA.

Received: 31 July 2014 Accepted: 16 December 2014

Published: 20 December 2014

\section{References}

1. Zhao G, Ford ES, Li C, Croft JB: Serum 25-hydroxyvitamin D levels and all-cause and cardiovascular disease mortality among US adults with hypertension: the NHANES linked mortality study. J Hypertens 2012, 30(2):284-289.

2. Messenger W, Nielson CM, Li H, Beer T, Barrett-Connor E, Stone K, Shannon J: Serum and dietary vitamin $D$ and cardiovascular disease risk in elderly men: a prospective cohort study. Nutr Metab Cardiovasc Dis 2012, 22(10):856-863.

3. Holick MF: Vitamin D deficiency. N Engl J Med 2007, 357(3):266-281.

4. Wang TJ, Pencina MJ, Booth SL, Jacques PF, Ingelsson E, Lanier K, Benjamin EJ, D'Agostino RB, Wolf M, Vasan RS: Vitamin D deficiency and risk of cardiovascular disease. Circulation 2008, 117(4):503-511.

5. Targher G, Bertolini L, Padovani R, Zenari L, Scala L, Cigolini M, Arcaro G: Serum 25-hydroxyvitamin D3 concentrations and carotid artery intima-media thickness among type 2 diabetic patients. Clin Endocrinol (Oxf) 2006, 65(5):593-597.

6. Wang L, Song Y, Manson JE, Pilz S, März W, Michaëlsson K, Lundqvist A, Jassal SK, Barrett-Connor E, Zhang C, Eaton CB, May HT, Anderson JL, Sesso HD: Circulating 25-hydroxy-vitamin D and risk of cardiovascular disease: a meta-analysis of prospective studies. Circ Cardiovasc Qual Outcomes 2012, 5(6):819-829.

7. Deleskog A, Piksasova O, Silveira A, Gertow K, Baldassarre D, Veglia F, Sennblad B, Strawbridge RJ, Larsson M, Leander K, Gigante B, Kauhanen J, Rauramaa R, Smit AJ, Mannarino E, Giral P, Gustafsson S, Östenson CG, Humphries SE, Tremoli E, de Faire U, Öhrvik J, Hamsten A: Serum 25-hydroxyvitamin $D$ concentration in subclinical carotid atherosclerosis. Arterioscler Thromb Vasc Biol 2013, 33(11):2633-2638. 
8. Blondon M, Sachs M, Hoofnagle AN, Ix JH, Michos ED, Korcarz C, Gepner AD, Siscovick DS, Kaufman JD, Stein JH, Kestenbaum B, de Boer IH: 25-Hydroxyvitamin D and parathyroid hormone are not associated with carotid intima-media thickness or plaque in the multi-ethnic study of atherosclerosis. Arterioscler Thromb Vasc Biol 2013, 33(11):2639-2645.

9. Park S, Lee BK: Vitamin D deficiency is an independent risk factor for cardiovascular disease in Koreans aged $\geq 50$ years: results from the Korean National Health and Nutrition Examination Survey. Nutr Res Pract 2012, 6(2):162-168

10. Melamed ML, Michos ED, Post W, Astor B: 25-hydroxyvitamin D levels and the risk of mortality in the general population. Arch Intern Med 2008, 168(15):1629-1637.

11. Hypponen E, Berry D, Cortina-Borja M, Power C: 25 -Hydroxyvitamin D and pre-clinical alterations in inflammatory and hemostatic markers: a cross sectional analysis in the 1958 British Birth Cohort. PLoS One 2010, 5:e10801.

12. Mosca L, Barrett-Connor $E$, Wenger NK: Sex/gender differences in cardiovascular disease prevention: what a difference a decade makes. Circulation 2011, 124(19):2145-2154

13. Ma H, Lin H, Hofman A, Hu Y, Li X, He W, Jeekel J, Jin X, Gao J, Zhao N, Gao X: Low-grade albuminuria is associated with carotid atherosclerosis in normotensive and euglycemic Chinese middle-aged and elderly adults: the Shanghai Changfeng Study. Atherosclerosis 2013, 228(1):237-242.

14. Gao X, Hofman A, Hu Y, Lin H, Zhu C, Jeekel J, Jin X, Wang J, Gao J, Yin Y, Zhao $\mathrm{N}$ : The Shanghai Changfeng Study: a communitybased prospective cohort study of chronic diseases among middle-aged and elderly: objectives and design. Eur J Epidemio/ 2010, 25(12):885-893.

15. Levey AS, Bosch JP, Lewis JB, Greene T, Rogers N, Roth D: A more accurate method to estimate glomerular filtration rate from serum creatinine: a new prediction equation. Modification of Diet in Renal Disease Study Group. Ann Intern Med 1999, 130(6):461-470

16. Matthews DR, Hosker JP, Rudenski AS, Naylor BA, Treacher DF, Turner RC Homeostasis model assessment: insulin resistance and beta-cell function from fasting plasma glucose and insulin concentrations in man. Diabetologia 1985, 28(7):412-419.

17. Stein JH, Korcarz CE, Hurst RT, Lonn E, Kendall CB, Mohler ER, Najjar SS, Rembold CM, Post WS: American Society of Echocardiography Carotid Intima-Media Thickness Task Force: Use of carotid ultrasound to identify subclinical vascular disease and evaluate cardiovascular disease risk: a consensus statement from the American Society of Echocardiography. Carotid intima-media thickness Task Force Endorsed by the Society for vascular Medicine. J Am Soc Echocardiogr 2008, 21(2):93-111.

18. Chobanian AV, Bakris GL, Black HR, Cushman WC, Green LA, Izzo JL Jr, Jones DW, Materson BJ, Oparil S, Wright JT Jr, Roccella EJ; Joint National Committee on Prevention, Detection, Evaluation, and Treatment of High Blood Pressure. National Heart, Lung, and Blood Institute; National High Blood Pressure Education Program Coordinating Committee: Seventh report of the joint national committee on prevention, detection, evaluation, and treatment of high blood pressure. Hypertension 2003, 42(6):1206-1252

19. American Diabetes Association: Standards of medical care in diabetes-2010. Diabetes Care 2010, 33(suppl 1):S11-S61.

20. Liu L, Chen M, Hankins SR, Nũñez AE, Watson RA, Weinstock PJ, Newschaffer CJ, Eisen HJ: Drexel Cardiovascular Health Collaborative Education, Research, and Evaluation Group: Serum 25-hydroxyvitamin D concentration and mortality from heart failure and cardiovascular disease, and premature mortality from all-cause in United States adults. Am J Cardiol 2012, 110(6):834-839.

21. Simon A, Megnien JL, Chironi G: The value of carotid intima-media thickness for predicting cardiovascular risk. Arterioscler Thromb Vasc Biol 2010, 30(2):182-185.

22. Kim SH, Reaven $\mathrm{G}$ : Sex differences in insulin resistance and cardiovascular disease risk. J Clin Endocrinol Metab 2013, 98(11):E1716-E1721.

23. Qiao Z, Li-Xing S, Nian-Chun P, Shu-Jing X, Miao Z, Hong L, Hui-Jun Z, Ming-Xian G, Song Z, Rui W, Ying H, Jing-Lu Z, Shuang C: Serum 25(OH)D Level and Parathyroid Hormone in Chinese Adult Population: A CrossSectional Study in Guiyang Urban Community from Southeast of China. Int J Endocrinol 2013, 2013:150461

24. Lu L, Yu Z, Pan A, Hu FB, Franco OH, Li H, Li X, Yang X, Chen Y, Lin X: Plasma 25-hydroxyvitamin $D$ concentration and metabolic syndrome among middle-aged and elderly Chinese individuals. Diabetes Care 2009, 32(7):1278-1283

25. Xue Y: Serum levels of 25-hydroxyvitamin D in normal Beijing subjects. China Prev Med 1991, 25(3):177-179.

26. Yan L, Zhou B, Wang X, D'Ath S, Laidlaw A, Laskey MA, Prentice A: Older people in China and the United Kingdom differ in the relationships among parathyroid hormone, vitamin $\mathrm{D}$, and bone mineral status. Bone 2003, 33(4):620-627.

27. Saedisomeolia A, Taheri E, Djalali M, Moghadam AM, Qorbani M: Association between serum level of vitamin $\mathrm{D}$ and lipid profiles in type 2 diabetic patients in Iran. J Diabetes Metab Disord 2014, 13(1):7.

28. Mattila C, Knekt P, Männistö S, Rissanen H, Laaksonen MA, Montonen J, Reunanen A: Serum 25-hydroxyvitamin D concentration and subsequent risk of type 2 diabetes. Diabetes Care 2007, 30(10):2569-2570.

29. Grandi NC, Breitling LP, Vossen CY, Hahmann H, Wüsten B, März W, Rothenbacher D, Brenner $H$ : Serum vitamin D and risk of secondary cardiovascular disease events in patients with stable coronary heart disease. Am Heart J 2010, 159(6):1044-1051.

30. Gouni-Berthold I, Krone W, Berthold HK: Vitamin D and cardiovascular disease. Curr Vasc Pharmacol 2009, 7(3):414-422

31. Li YC, Kong J, Wei M, Chen ZF, Liu SQ, Cao LP: 1,25-Dihydroxyvitamin D(3) is a negative endocrine regulator of the renin-angiotensin system. $J$ Clin Invest 2002, 110(2):229-238

32. Li YC: Vitamin D regulation of the renin-angiotensin system. J Cell Biochem 2003, 88(2):327-331.

33. Rammos G, Tseke P, Ziakka S: Vitamin D, the renin-angiotensin system, and insulin resistance. Int Urol Nephrol 2008, 40(2):419-426.

34. Ohsawa M, Koyama T, Yamamoto K, Hirosawa S, Kamei S, Kamiyama R: 1alpha,25-dihydroxyvitamin $\mathrm{D}(3)$ and its potent synthetic analogs down-regulate tissue factor and up-regulate thrombomodulin expression in monocytic cells, counteracting the effects of tumor necrosis factor and oxidized LDL. Circulation 2000, 102(23):2867-2872.

35. Van der Schueren BJ, Verstuyf A, Mathieu C: Straight from D-Heart: vitamin D status and cardiovascular disease. Curr Opin Lipidol 2012, 23(1):17-23.

36. Schmidt N, Brandsch C, Kühne H, Thiele A, Hirche F, Stangl Gl: Vitamin D receptor deficiency and low vitamin $D$ diet stimulate aortic calcification and osteogenic key factor expression in mice. PLoS One 2012, 7(4):e35316.

37. Brandenburg VM, Vervloet MG, Marx N: The role of vitamin D in cardiovascular disease: from present evidence to future perspectives. Atherosclerosis 2012, 225(2):253-263.

38. Deluca HF, Cantorna MT: Vitamin D: Its role and uses in immunology. Faseb J 2001, 15(14):2579-2585.

39. Zittermann A1, Schleithoff SS, Tenderich G, Berthold HK, Körfer R, Stehle P: Low vitamin D status: a contributing factor in the pathogenesis of congestive heart failure? J Am Coll Cardiol 2003, 41(1):105-112.

40. Oh J, Weng S, Felton SK, Bhandare S, Riek A, Butler B, Proctor BM, Petty M, Chen Z, Schechtman KB, Bernal-Mizrachi L, Bernal-Mizrachi C: 1,25(OH)2 vitamin $d$ inhibits foam cell formation and suppresses macrophage cholesterol uptake in patients with type 2 diabetes mellitus. Circulation 2009, 120(8):687-698.

doi:10.1186/1471-2261-14-197

Cite this article as: Ma et al:: Serum 25-hydroxyvitamin D levels are associated with carotid atherosclerosis in normotensive and euglycemic Chinese postmenopausal women: the Shanghai Changfeng study. BMC Cardiovascular Disorders 2014 14:197. 